\title{
EFFECT OF RELIGION, ETHICS AND CULTURE ON BUSINESS
}

\section{SITIKANTHA MISHRA \& BIBHUTI B PRADHAN}

Research Scholar, Department of Management, Siksha 'O' Anusandhan (Deemed to be University),

Bhubaneswar, Odisha, India

\begin{abstract}
This paper work seeks to examine how various faiths affect entrepreneurship ethics. It create an index on corporate ethics standards, composed on 18 elements that include activities relevant to employees, clients, goods and civil rights, ethical problem resolution and crime reduction. Here a large number of religious affiliations is normally found. The findings obtained indicate that in the nation where an organization does business, a higher percentage of religious practitioners typically require enforcing more ethical standards in the corporate sector. For Christian, Islamic, Jewish, and Hindu faiths, such results are collected. That, on the other side, is not in favor of Buddhist and traditional faiths. Countries where no prevalent faith occurs often may not show a confluence of faith and responsible business activity. Knowing the two cultures origin and history will contribute to an appreciation of the foundation of their ethical structures. Ethics and standards influence all commercial activities within the cultures. It's important that Western advertisers grasp their peer's aspirations around the globe. Implementing the information through a simple collection of management rules will turn the importance of that insight into practice."
\end{abstract}

KEYWORDS: Business Ethics, Culture, Productivity, Religion

Received: Jun 08, 2020; Accepted: Jun 28, 2020; Published: Aug 26, 2020; Paper Id.: IJMPERDJUN2020907

\section{INTRODUCTION}

Religion has played a central position in most cultures over the years, particularly in influencing the societal environment that is deeply affected by religious values and organizations worldwide. At the same time, it may impact ethics standards established by companies, either by personal beliefs of people or by their effect on society, contributing to a collection of societal norms. The theoretical framework which may connect various religions to the business integration approach could be focused on stakeholder theory[1].As Retolaza, Aguado, and Alcaniz suggest, this philosophy pays special attention to the numerous social and economic forces that relate to society, stressing that corporate strategy cannot be based exclusively on the desires of shareholders, but must incorporate the needs of the remaining stakeholders, generating meaning for each stakeholder in pursuit of the common good. Therefore, the primary aim is to build interest for every stakeholder contributing to the company, and not only to achieve economic benefit. Considering the business as an entity that is not only economic, but also social, would also promote ethical activities within organizations and view the effect on their society from the stakeholder theory perspective.

In this sense, by having the same viewpoint, religions often improve a corporate ethical philosophy that goes beyond solely economic aims and pursues the fundamental growth of people. Previous studies on the effect of various religions on business ethics have shown that religions are supposed to enhance ethical decision-making and the adoption of a higher numbness. In this way, religiosity can affect "attitudes, beliefs, judgments, and eventually actions of a person." However, work on the impact of faith on ethical business practices has not provided definitive findings, indicating that religiosity does not mean ethical conduct directly. Vitell argues that there is proof that 
religious individuals are more inclined to establish better ethical principles and decisions in the company sense than those with weaker values. Religion should also be viewed as providing a very favorable association with corporate ethical decision-making, at least in terms of its effect on views, behavior and ethical decisions. Singhapakdi, Marta, Rallapalli, and Rao or Quazi get reasons in support of healthy partnerships between belief, ethical interpretation and moral goals in the same section[2]. Quazi also found that the greater the religious convictions, the more possible it will be for the boss to view moral and ethical responsibility outside the tight regulatory conditions. However, Weaver and Agle and Vitell emphasize that religion may affect perceptions and attitudes toward an ethical question, though not inherently the ultimate ethical conduct, a topic on which literature fails to find definitive results.

Kurpis, Beqiri, and Helgeson found that religiosity may not specifically affect the perception of ethical issues and behavioral motives, but it may, to some degree, result in a stronger dedication to spiritual self-improvement, and that may impact the perceived value of ethics. And there is a lot of research to do to grasp this friendship thoroughly. This paper seeks to expand the above-mentioned discussion and to add in many respects to the current literature. First, we establish an index of professional ethics, pointing to the various activities in several fields of an organization that can be used to examine the most important facets of corporate ethics in the international domain. Second, it research the influence of various globally recognized religions, certain research centered exclusively on a single religion.

\section{STAKEHOLDER PHILOSOPHY OF ETHICS OF BUSINESS}

Centered on Friedman's claims, increasing economic income is the key aim the companies seek over time. However, culture has slowly established a new form of treating businesses. Stakeholder philosophy supports this approach that the company's goal is to build interest for all its stakeholders. Richter and Dow underline how stakeholder theory redefines organizations as a diverse community of stakeholders, establishing an alignment of partnerships between individuals of different interests, priorities, aspirations and obligations[3].Thus, as Freeman and Auster hold, the aim of a business is not only to return income, as it must always take into account the interests, positions and stakes of all the organization's members. Thus, these participants are stakeholders, identified as any category of persons who can or may be influenced by the accomplishment of the organization's goals. Thus, the value of the others position, outside shareholders, is crucial to the stakeholder theory's proposals.

This strategy has certainly legal consequences for the corporate field. According to Alford this emphasis respects the human integrity of each stakeholder, and aims to view each as a target of its own right. Therefore, in this philosophy the ethical approach is to support the collective interests of actors within a system of accountability. While individuals have their own priorities, they participate in a collective mission that benefits society at the same time. This universal view of human beings, being willing to overcome their own uniqueness and display empathy for the other, represents a societal structure and a constructive image of society. Many scholars emphasize how different social and economic influences relate while stressing that shareholders are not the only ones involved in corporate governance. Many interests should be regarded in the pursuit of the common good, which can be described as the overall conditions of existence in society that make it harder for the various groups and their leaders to attain their own success.

The ethical decision-making can also be grounded in stakeholder philosophy[4]. As Freeman says, the central principle of the hypothesis is to contradict the distinction argument, distinguishing between the market discourse and the ethics discourse. An integrative perception of responsibility for the numerous communities impacted by the actions of an organization needs an ethical aspect, with special focus on dialog and interaction. 
According to Fassin there are three separate stakeholder groups: actual stakeholders (who are accountable for a business as they have a legal point, control and influence), stakeholders (who do not have a direct stake, but instead serve, for example, environmental protection organizations or customer interests) and stakeholders (mainly autonomous stakeholders).

Within that sense, three qualities of stakeholders are listed by Mitchell, Agle, and Wood (1997). First, stakeholders need the ability to control companies; ability must therefore set and prioritize the expectations of stakeholders. Secondly, authority grants privileges through force, which defines to what degree corporations have legal and moral obligations. Finally, pressure calls for the urgent execution of certain stakeholder demands.

Such characteristics help stakeholders to reach the business goals suggested. The principle of stakeholders was brought forth in favor of the reasons and reasoning for Corporate Social Responsibility CSR. However, several of the existing CSR viewpoints have also been developed and established by ideologies, such as the war against hunger or the advancement of human growth. The philosophy of stakeholders encourages the social good of society by business action and wealth development with each group belonging to a corporation and not only economic benefits, or through an interest in it. Therefore, companies are not merely economic bodies, as they are often social organizations, and should promote ethical standards when considering their effect. Along these lines, as religions have the same viewpoint, they should also foster a corporate ethical agenda beyond solely economic aims, and seek individual's fundamental growth.

Given the value of stakeholder theory for ethical reasons, certain elements require explanation. For example a more indepth study could be made of meeting various stakeholder demand, while at the same time incorporating marginal stakeholders or implementing suitable stakeholder deliberation schemes.

\section{ETHICS IN BUSINESS BY VARIOUS RELIGIONS AND THEORIES}

In the business world, religions may affect ethical standards[5], either through the moral beliefs of people or through their impact on society, giving rise to a collection of social norms. In this segment, we concentrate on the views on business ethics established by the major religions, considering that each faith may have a varying degree on impact over its own culture. The religions often vary, as Cui and Jo claim, as they have separate collection of principles. While in some instances a desire to distinguish business from ethics may be observed, and managers in their office contrast their religious engagement and their regular activities, both religious creeds originating from the Bible agree in fact that corporate existence is an essential aspect of personal religion and a significant area of religious activity.

Moreover, regardless of the religious views of individuals, once a religion appears as a standard in culture, the religiosity of a group will influence corporate decisions and individual actions. Not only can religious societal customs have a heavy effect on their immediate followers, but they may also impact and change the actions of non-believers to some degree through their commitment to social conformity. Therefore, particular attention should be put on the role of faith as a significant cultural element to research, as an integral promoter of a system of social standards impacting multiple aspects. Likewise, where there are a sufficient number of religious people in a specific region, businesses in that field would continue to employ a higher proportion of religious people at all levels of the company. Similarly, while administrators are not inherently committed practitioners of a single faith, there is a higher probability of engaging with adherents in certain areas where a large portion of the community is religious[6]. Just as stated in the Interfaith Agreement, the most practiced religions hold certain shared principles that direct the actions of adherents and have consequences for business operations. 
Therefore, religions based on the Bible contain four main principles that are specifically incorporated in corporations: fairness, shared responsibility, stewardship and integrity. The Western theological tradition therefore reaffirms the value of ethical behavior in industry and opposes the view of corporate existence as a distinct domain of ethical responsibility for practitioners. In view of Christianity as Western world's most comprehensive faith, Christian precepts mold corporate ethics by their effect on law and society, advocating ethics focused on compassion and service to others. While there is no structured economic philosophy in the gospels, they also provide a view of behavior focused on another, which often involves business concerns. As Melé and Frontrodon say, Christianity, among most faiths, includes several business ethical values and fosters ideals, putting together important ideas that are commonly utilized in corporate ethics today, such as individual integrity or natural resource stewardship. Christian religiosity also, as demonstrated by Cui and Jo, helps administrators to support human rights.

Three large creeds may be defined within Christianity, with specific emphases on commercial activity: Catholicism, Protestantism, and Orthodox Christians. Historically, Catholicism has concentrated primarily on social justice concerns, rather than corporate ethics per se.It reaffirms the centrality of human integrity as the cornerstone and purpose of economic existence. As far as Protestantism is concerned, As Green states, no theological practice has had a greater influence than Protestantism in influencing the attitudes of this society towards business and ethics. Since its inception, it has developed a system of ethical and moral principles that promote and maintain economic and corporate existence. Economic prosperity is seen as a sign of wealth, while poverty is related to moral and spiritual failure, especially unwillingness to function. Pioneering in the concept of job ethics, Protestantism has concentrated on economic prosperity as the primary objective of corporate existence. We may also discern Conservatism, which is more likely to secure the climate for potential generations, even though it means slowing economic development. So, for such adherents, environmentalism tends to be a universal value; in addition, most Orthodox Christians agree that the world must be preserved[7].

Islamic faith entails a philosophy, a vision of the universe, and a lifestyle with a significant effect on any part of the believer's existence, both public and private, political and cultural. Therefore, its recommendations in business operations are important. This is a legalistic religion that needs certain commitments from its adherents, providing a restricted number of flexibilities. This is a legalistic religion that needs specific guarantees from its adherents, providing only a restricted degree of autonomy or adaptation to cultural circumstances. This combines Christianity and Judaism with certain spiritual values, such as equality, fairness, integrity, trustworthiness, and concern for the poor. Muslims therefore derive their ethical code from the Koran, which deals with virtually every part of life. From this point of view, employment is regarded as worship, commerce and growth are promoted and the equal distribution of income is pursued within community.

The Islamic job ethics also encourages a productive nature in the workplace and a constructive mindset of solidarity towards others. Muslims are also expected to engage in practices under the basis that all increase in material development contributes to social justice and moral change, and that they are generally opposed to demand and competitiveness in contrast with other faiths. Therefore ethical attitudes and actions are encouraged in the business sector. Judaism is an ancient faith, on whose foundation the Scripture includes lessons about ethical conduct and social justice.

Hinduism is one of the most excellent religions in terms of its effects on business ethics, but until recently this influence was scarcely studied. For a Hindu, life aspirations are not only about moksha, or divine liberation, but also about artha, or material wellbeing. The ancient theological development frameworks based on Hinduism emphasize the value of 
extending ethical concepts to all aspects of existence. Indeed, Hinduism is seen as a religion, as it gives a realistic view of the environment and a lifestyle. It is a code of ethics focused on moral principles, it typically exhibits an approach opposed to business and competitiveness, and demonstrates a firm aversion to bribery. Berger and Herste in explain that business ethics has gained that attention as a business necessity and are seen as a critical norm for business performance, especially in a Hindu community. Folk religion is basically the ethnic or tribal religious practices performed under the illusion of an existing and uniform faith. Indeed, there are indigenous or native beliefs everywhere, especially in some sections of South America, Africa, China and South-East Asia. Some scholars identify it as a diffused faith, in which recorded history and scriptures do not exist. Folk religion originates from existing creeds or world-religions like Hinduism, Buddhism, Christianity, or Islam. And "the viewpoint of folk religion is profoundly alive, unlike the empirical viewpoint of other religions, adherents encounter religious predictably directly through purposeful action, particularly ritual. It is present in several nations, such as China India, Taiwan or Japan. Holds close links to Buddhism, Taoism, or Confucianism[8].

Folk religions have historically been central to defining the character of community and culture, while they are currently confronting influences of globalization that have undermined their significant position. Some similar features stand out among the various viewpoints of folk religion worship of nature, worship of ancestors, and worship of protective deities, ecological thinking and emphasis on simplicity and community growth. The quest for a state of equilibrium with nature and a conventional openness towards it both help to describe its principal origins. Moreover, the role of confidence and implicit affective relations and networks in such cultures continues to define a social outlook. Folk religion appreciates the centrality of morality and benevolence along with certain universal principles such as reciprocity in handling others. It also affirms human nature's fairness, and encourages virtues. The proposals put forth by folk religion and traditions may also have a preventive impact on immoral activities, as seen by Szeto with the goal of fostering trustworthiness and establishing harmonious partnerships between various sections of a society, provided the importance provided to group growth. The evolutionary philosophy often allows them more responsive to nature.

In countries where this form of religion is developed, they can supplement Western ethical strategies, and can affect organizational decisions taken by managers. In addition, it should be remembered that, in company, religions offer an integrative strategy, paying attention to numerous social and economic players. Thus, while they prefer to concentrate on various traditions and worship methods, they agree in suggesting a corporate ethics system that follows certain shared principles. This method may be integrated into stakeholder theory[9].For example, Catholicism says that corporate management does not rely exclusively on the needs of shareholders, but should include the needs of all stakeholders (workers, consumers, vendors, etc.) who make a difference to the enterprise. The quest for the greater good is the foundation of both faith and stakeholder philosophy, considering the needs of each stakeholder and generating meaning for all stakeholders, beyond simply achieving economic benefits. Accordingly, from the stakeholder philosophy viewpoint, seeing corporations as not just economic but also social entities would contribute to the development of ethical activities within[10].

\section{CONCLUSIONS}

The theory of stakeholders views corporations as entities that are not only economic but also social, thereby promoting ethical activities within organizations that influence their background. From this viewpoint, we explored the impact of various faiths on ethical standards by constructing a model composed of 18 elements that include ethical practices related to workers, clients, substance, human rights, ethical dispute management and crime reduction. This research suggests that there is a connection between Christianity, Islam, Judaism and Hinduism and the growth of business-related ethical 
practices. Companies follow a broader variety and volume of business ethics activities in areas where there is a large proportion of practitioners in such faiths. This result is compatible with stakeholder philosophy, which stresses how companies seek certain purposes outside the pure economic income. This research suggests that there is a connection between Christianity, Islam, Judaism and Hinduism and the growth of business-related ethical practices. Companies follow a broader variety and volume of business ethics activities in areas where there is a large proportion of practitioners in such faiths. This result is compatible with stakeholder philosophy, which stresses how companies seek certain purposes outside the pure economic income.

\section{REFERENCES}

1. F. Wiengarten, P. Humphreys, C. Gimenez, and R. McIvor, "Risk, risk management practices, and the success of supply chain integration," Int. J. Prod. Econ., 2016, doi: 10.1016/j.ijpe.2015.03.020.

2. R. Berger and R. Herstein, "The evolution of business ethics in India," Int. J. Soc. Econ., 2014, doi: 10.1108/IJSE-05-20130129.

3. K. P. Parboteeah, S. G. Walter, and J. H. Block, "When Does Christian Religion Matter for Entrepreneurial Activity? The Contingent Effect of a Country's Investments into Knowledge,” J. Bus. Ethics, 2015, doi: 10.1007/s10551-014-2239$z$.

4. L. Z. Wu, H. K. Kwan, F. H. kit Yim, R. K. Chiu, and X. He, "CEO Ethical Leadership and Corporate Social Responsibility: A Moderated Mediation Model,” J. Bus. Ethics, 2015, doi: 10.1007/s10551-014-2108-9.

5. R. E. Freeman, Strategic management: A stakeholder approach. 2015.

6. A. C. Michalos and D. C. Poff, “Journal of Business Ethics," in Encyclopedia of Business and Professional Ethics, 2018.

7. A. B. Carroll and A. K. Buchholtz, "Business and society: Ethics and stakeholder management," Annual review of sociology. 2012, doi: 10.1007/s13398-014-0173-7.2.

8. X. Zhan and C. Kim, "Nankai Business Review International Article information:," Nankai Bus. Rev. Int., 2015, doi: 10.1108/NBRI-04-2016-0013.

9. R. E. Freeman, J. S. Harrison, A. C. Wicks, B. Parmar, and S. de Colle, Stakeholder theory: The state of the art. 2010.

10. E. W. Mainardes, H. Alves, and M. Raposo, "Stakeholder theory: Issues to resolve," Management Decision. 2011, doi: 10.1108/00251741111109133. 